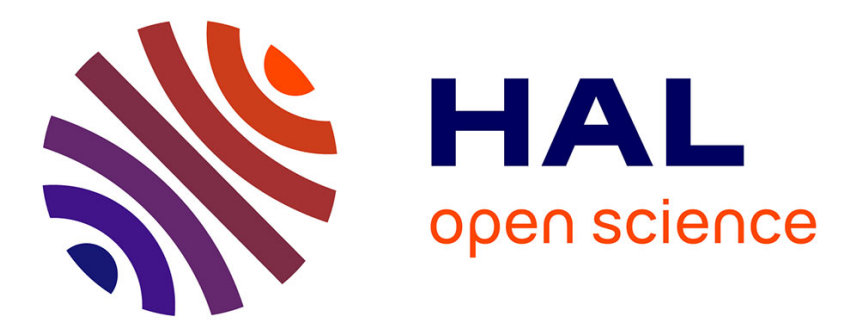

\title{
Improvement of antenna measurement results at low frequencies by using post-processing techniques
} Gwenn Le Fur, Francisco Cano-Facila, Francesco Saccardi, Daniel Belot, Ludovic Durand, Luc Duchesne, L.J. Foged, Jean-Marc Lopez, Anthony Bellion

\section{To cite this version:}

Gwenn Le Fur, Francisco Cano-Facila, Francesco Saccardi, Daniel Belot, Ludovic Durand, et al.. Improvement of antenna measurement results at low frequencies by using post-processing techniques. Antennas and Propagation (EuCAP), 2014 8th European Conference on, Apr 2014, Den Haag, Netherlands. 10.1109/EuCAP.2014.6902112 . hal-01253520

\section{HAL Id: hal-01253520 https://hal.science/hal-01253520}

Submitted on 11 Jan 2016

HAL is a multi-disciplinary open access archive for the deposit and dissemination of scientific research documents, whether they are published or not. The documents may come from teaching and research institutions in France or abroad, or from public or private research centers.
L'archive ouverte pluridisciplinaire HAL, est destinée au dépôt et à la diffusion de documents scientifiques de niveau recherche, publiés ou non, émanant des établissements d'enseignement et de recherche français ou étrangers, des laboratoires publics ou privés. 


\title{
Improvement of Antenna Measurement Results at Low Frequencies by Using Post-processing Techniques
}

\author{
Gwenn Le Fur ${ }^{1}$, Francisco Cano-Facila ${ }^{1}$, Francesco Saccardi ${ }^{1}$, Daniel Belot ${ }^{2}$, Ludovic Durand ${ }^{1}$, \\ Luc Duchesne $^{1}$, Lars Jacob Foged ${ }^{1}$, Jean-Marc Lopez ${ }^{2}$ and Anthony Bellion ${ }^{2}$ \\ ${ }^{1}$ MVG - SATIMO, Villebon sur Yvette, France, Gwenn.le-fur@ satimo.fr \\ ${ }^{2}$ CNES (French National Space Center), DCT/RF/AN, Toulouse, France, Daniel.belot@cnes.fr
}

\begin{abstract}
This paper presents a part of a whole study dedicated to the design of an indoor near-field antenna measurement system in VHF range. During this study a new wide band probe covering the 50 to $400 \mathrm{MHz}$ bandwidth was developed, manufactured and characterized. The paper will focus on the use of post-processing techniques to improve measurement results. Measurements have been done in two different systems. Results are given to show the capability of Time Domain filtering and Equivalent Current Approach to reduce ripples due to reflections and truncation effect.
\end{abstract}

Index Terms - antenna measurement, low frequencies, VHF, post-processing techniques.

\section{INTRODUCTION}

Recent enhancements in military telecommunication systems for monitoring and tracking in low VHF range (30-80 $\mathrm{MHz}$ ) imply the use of specific antenna measurement facilities to characterize either the antenna alone or the antenna mounted on a supporting structure which can be heavy and bulky. Conventional outdoor far-field antenna measurement ranges used at UHF frequency bands and above become poorly effective down in VHF frequency band due to ground effects and electromagnetic pollution. Other implementations such as indoor far-field or compact range are not suitable at these very large wavelengths. A brief state of the art of existing VHF measurement facilities has been done in [1]. The indoor Near-Field approach shows benefits in terms of compactness. However this approach involves issues due to high levels of reflectivity of the anechoic chamber, the Antenna Under Test (AUT) positioner and the measurement probe structure at these frequencies. Studies and characterizations of each component effect have been performed in a previous paper [2].

The proposed paper focuses on measurement results improvements of a new VHF probe using post processing techniques. First is briefly presented the new $50-400 \mathrm{MHz}$ dual polarized probe. Then the two different measurement systems used are described. Post-processing techniques are then discussed and chosen to answer to inherents measurement system issues. Finally results are given to show the capability of Time Domain filtering and Equivalent
Current Approach to reduce ripples due to reflections and truncation effect.

\section{SATIMO VHF WIDE BAND PROBE}

A new wide band and dual polarized VHF probe has been designed and manufactured. Mass and mechanical stability were critical points for this voluminous antenna as shown in Figure 1 with a weight around $70 \mathrm{~kg}$ and dimensions of $2 \times 2$ $\mathrm{x} 1.7 \mathrm{~m}$. A mechanical analysis has been performed and the chosen main constituting material is the Metawell [3]. Return losses for each polarization are below $-10 \mathrm{~dB}$ as shown in Figure 1. Isolations between polarizations are better than 20 $\mathrm{dB}$ over the 50 to $400 \mathrm{MHz}$ bandwidth.
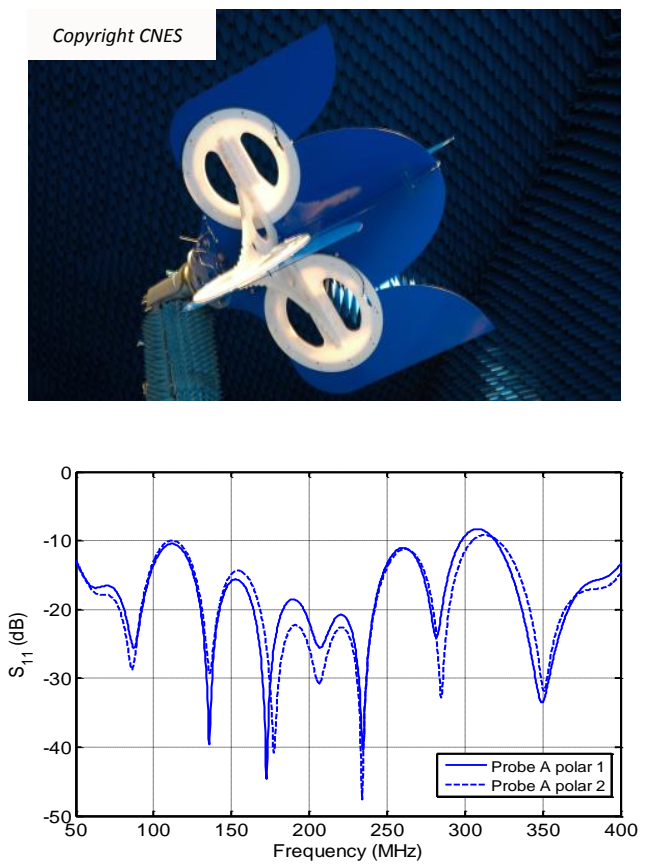

Figure 1 Photograph of the $50-400 \mathrm{MHz}$ dual polarized probe and measured return losses versus frequency 


\section{MEASUREMENT SYSTEMS}

\section{A. CNES Toulouse France}

The first measurement facility used is the single probe spherical near field measurement system located in the chamber of the CNES in Toulouse France. This facility is dedicated to perform antenna measurement from $80 \mathrm{MHz}$ to $200 \mathrm{GHz}$ [4]. The chamber is shared by a compact range measurement system and a single probe near-field system. Above $400 \mathrm{MHz}$ the compact range configuration is used. Below $400 \mathrm{MHz}$ the near-field configuration is used. Nevertheless classical foam pyramidal absorbers are poorly efficient below $200 \mathrm{MHz}$. Therefore ripples due to reflections coming from the compact range reflector and from the chamber walls were expected.

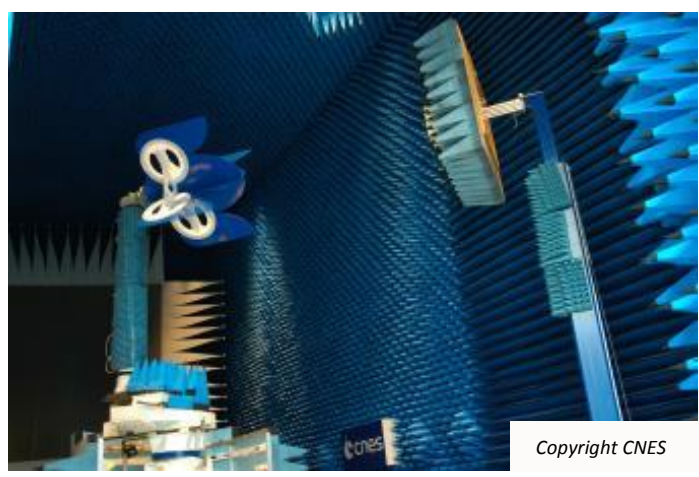

Figure 2 Photograph of the Near Field measurement configuration inside the CNES Compact Range

\section{B. Renault Aubevoye France}

The second system used is the multi-probe hemi-spherical near-field range located at the Renault Center in Aubevoye France [4]. The bandwidth of operation is from $70 \mathrm{MHz}$ to 6 GHz. In this second case the very large absorbers present a better absorption than the CNES chamber ones being acceptable from $125 \mathrm{MHz}$. Moreover no reflecting plane is present therefore less ripples due to reflections were expected. However the main error in this system comes from the measurement surface which is truncated at 102 degrees in elevation. Then ripples due to this truncated surface were expected.

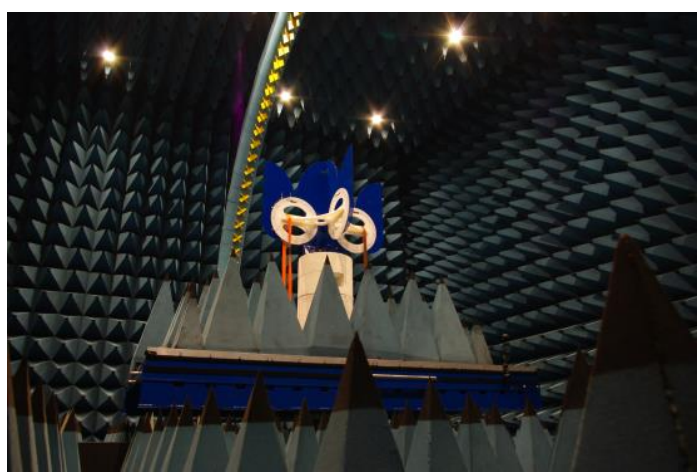

Figure 3 Photograph of the Renault Range

\section{Post-PROCESSING TECHNIQUES}

As commented before, because the antenna is measured at very low frequencies, one important error contribution are the reflections coming from the surrounding walls which are covered with absorbers but which are not able to effectively remove them due to their poor reflectivity behavior at these frequencies. The number of approaches to analyze and cancel the effects of these unwanted contributions has increased in recent years. There are methods that are employed not to remove the reflection waves, but rather to characterize the chambers by a figure of merit, usually called the reflectivity level [5]-[7]. Other solutions within the category of so-called compensation methods can be applied to avoid measuring the antenna under test several times at different distances with respect to the probe. Test zone field compensation [8] is one of these methods, and it is used to reduce the effects of undesired fields created by reflections, employing only the data from one measurement performed over a spherical surface. The main drawback of this last technique is the computational complexity, which can be reduced as shown in [9], in which the unwanted reflected components are associated with plane waves with which the error patterns are estimated. Other possible approaches include frequency decomposition techniques, where the signal measured in the frequencydomain is divided into a set of propagating components, including the direct and all the reflected contributions. Next, taking only the desired component, a result quite similar to the one obtained in a fully anechoic chamber may be achieved. The most popular techniques to carry out such decomposition use Prony's algorithm [10], pencil-of-function method [11] or matrix pencil method [12]. Another solution is to perform the measurement with the antenna shifted from the origin and then to apply a modal filtering [13]. In this last technique, the antenna must be located several wavelengths far away from the origin, therefore, in our particular case where low frequencies are use, it is not possible to apply this technique. Other last group of techniques is based on diagnostic techniques with which the field is reconstructed on a surface close to the antenna [14]-[15]. In this domain, if the desired contributions coming from the antenna and the undesired contributions coming from reflections are not spatially coincident a spatial filtering can be applied to suppress the second ones. In the case of a single probe system where the reflection contribution is variable relative to the antenna under test, this approach is less suitable.

The second error contribution is linked to the fact that in the Renault system the measurement is not performed over a surface which fully enclosed the antenna. As a consequence, the true far-field pattern cannot be determined in the whole sphere and is only valid within the so-called reliable region. A second effect, which is caused by the discontinuity of the measured field at the edge of the scan surface, is the presence of a ripple even within the reliable region. There are different approaches which attempt to reduce the mentioned ripple by the application of proper window functions to the near-field data [16]. Another ripple reduction approach is proposed in [17]-[18] in which raised cosine amplitude and quadratic phase 
windows are shown to provide high accuracy. Although windowing techniques can greatly reduce erroneous ripples, an extra scan area is needed to obtain the same reliable region. If the scan area is not extended with the use of one of these techniques, the extent of the reliable region is reduced. There is a second group of approaches which do not attempt to reduce the ripple within the region in which the far-field pattern is reliable, but they attempt to obtain a good estimation of the true pattern outside of that region. Another strategy to reduce truncation errors is to rotate the AUT about one or more axes [19], measuring in different planes and combining them to increase the maximum validity angle. Logically, this technique requires a particular near-field to far-field transformation for each combination of plane acquisitions. In [20], the problem of truncation is addressed using a priori information about the AUT. The main idea of this approach is to estimate the nearfield data outside of the scanning area by extrapolating the measured data before calculating the far-field pattern. The $a$ priori information is employed to obtain a non-redundant and non-uniform representation [21] of the samples that are taken over the measurement surface. A new method that is based on the same principle, i.e., the use of a non-redundant sampling in the acquisition, was proposed in [22]. In this method, the truncation error is practically eliminated by also addressing points in surfaces external to the actual scanning area. Therefore, this method can be applied whenever the set-up allows the variation of the distance between the AUT and the probe. Recent publications also use a priori information about the AUT in an iterative algorithm to extrapolate the reliable portion of the calculated far-field pattern. This method was proposed for the planar near-field case in [23] and generalized for the most common measurement systems in [24].

In our particular case, a time domain filtering technique and an equivalent current approach are employed to suppress reflections and truncation errors, respectively. More information about these two techniques is given in the two following sub-sections.

\section{A. EQC approach}

Equivalent Current Approach (EQC) also called Integral Equation Approach [25] is performed by using the Insight software developed by Satimo [26].

Based on the acquired NF data, Insight computes the equivalent electric and magnetic currents on an arbitrary shaped reconstruction surface conformal to the test object. From the equivalent currents the field on the full measured surface can be evaluated. This process mitigates the pattern error due to scan truncation that otherwise would show as a ripple due to the zero padding of the NF data in the traditional NF-FF transformation [27].

The equivalent electric and magnetic currents computed by Insight on an equivalent surface conformal to the shape of the VHF probe are shown in Figure 4.

It should be noted that the equivalent reconstruction surface also acts as spatial filter [15], mitigating the unwanted effect of echoes or stray signals.

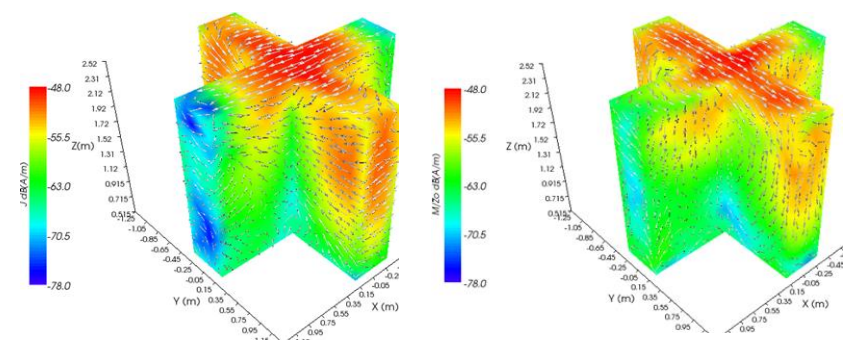

Figure 4 Examples of equivalent current sources for Renault (left: J currents, right: M currents)

\section{B. Time domain filtering}

Time domain filtering techniques or time-gating techniques are well-known approaches which can be employed as an option to remove reflected contributions. The main idea is to separate the direct signal from the reflections using a time-domain representation. In the initial approaches [28], [29], the measurement is directly performed in the timedomain by utilizing pulse generators and sampling oscilloscopes. After that, a time filtering and a time-tofrequency transformation are required to infer a reliable frequency response. However, the complexity of the pieces of equipment is lower when using frequency-domain measurements as proposed in [30], which is the technique used in our particular case to remove the effect of unwanted reflections as much as possible. Firstly, the measurement is performed over a wide enough frequency range. Using these data, the time response is immediately calculated by applying an inverse Fourier transform. If there are contributions coming from different places in the measurement set-up (different distances and therefore different times of arrival), it is very simple to identify them in this new domain. After that, direct contribution is detected and gated, eliminating the delayed response due to the reflected and diffracted components. Finally, a Fourier transform is applied to return to the frequency-domain.

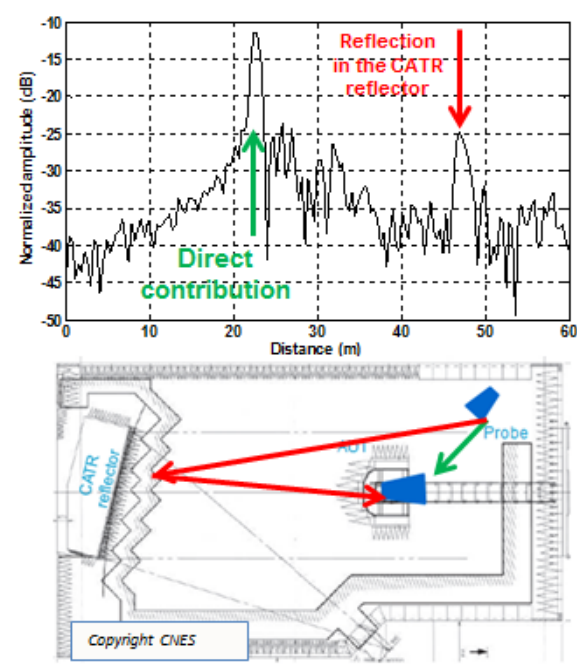

Figure 5 Example of time response in CNES chamber 


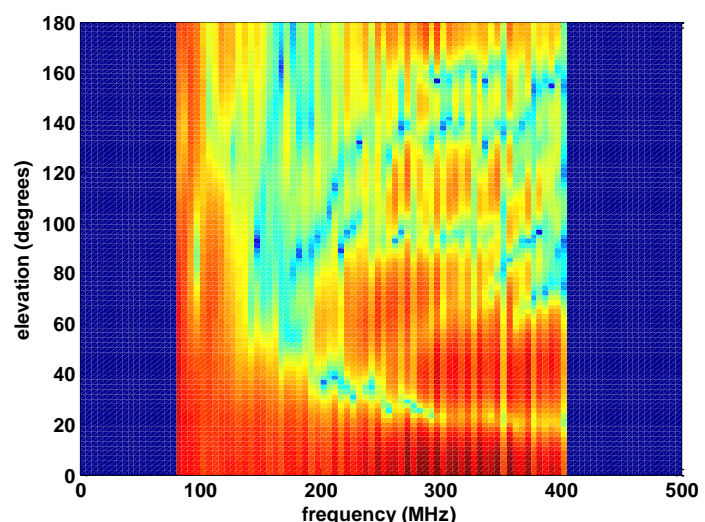

Figure 6 Example of radiated field before time filtering for one given azimuth - elevation versus frequency

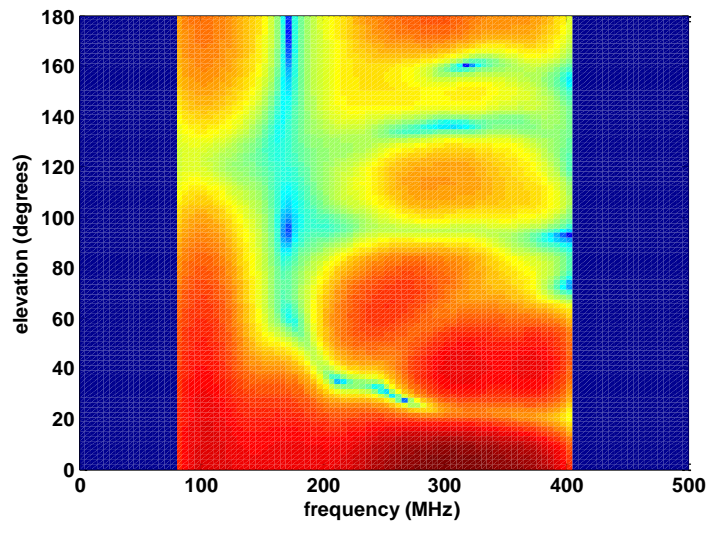

Figure 7 Example of radiated field after time filtering for one given azimuth - elevation versus frequency

Figure 5 shows the time domain response for one given direction. Direct and reflected contribution can easily be distinguished. The reflection coming from the CATR reflector is clearly identified regarding the time / distance occurrences. Figure 6 and Figure 7 present the frequency response before and after time filtering respectively for one given azimuth. Strong reduction of ripples can be observed.

\section{RESULTS}

The time filtering approach is applied in the results obtained in both measurement systems (CNES and Renault) to reduce reflections. However the EQC approach is only applied in the Renault measurement results for truncation matter.

Results examples at $100 \mathrm{MHz}$ of the post-processing are shown in Figure 8 (c) for the time filtering (TF) at CNES and in Figure 8 (e) for both time and EQC post-processing at Renault. The reference simulated result in shown Figure 8 (a). We observe good improvements of the results as shown in Figure 9 and Figure 10 for E plane at $100 \mathrm{MHz}$ and $200 \mathrm{MHz}$ respectively. More results at lower frequencies will be presented at the EuCAP Conference. Uncertainties estimation regarding these two measurement systems have now to be dressed when using these post-processing techniques.

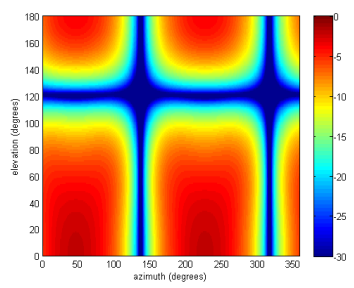

(a)

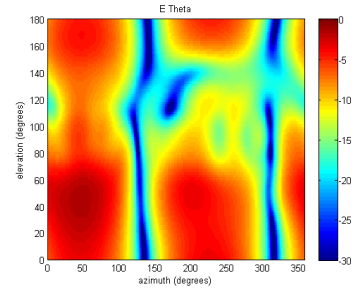

(b)

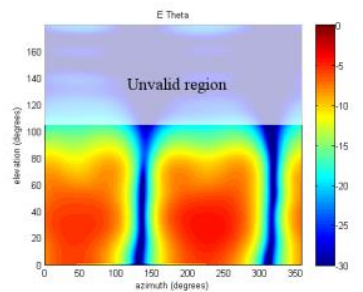

(d)

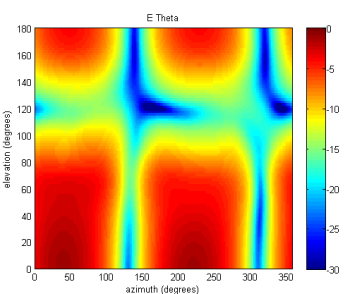

(c)

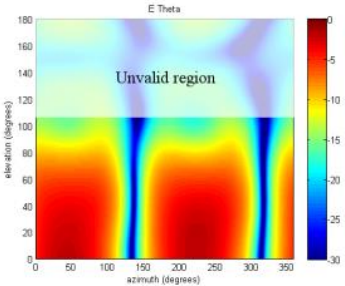

(e)
Figure 8 Examples of results at $100 \mathrm{MHz}$ Theta component - Elevation vs. azimuth plots (a) Simulation (b) CNES not filtered (c) CNES after time filtering (d) Renault not filtered (e) Renault after time and Insight processing

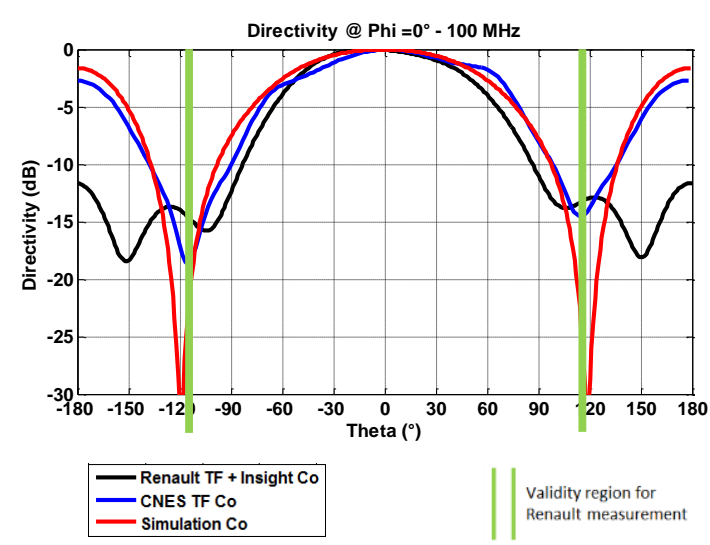

Figure 9 Comparison of radiation pattern cuts @ $100 \mathrm{MHz}$ (co-polarization) - E plane after processing - simulation, Renault and CNES measurement 


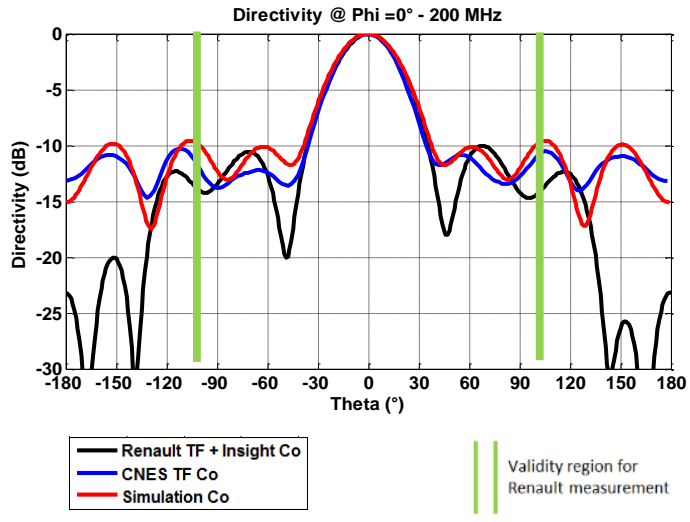

Figure 10 Comparison of radiation pattern cuts @ 200MHz (co- polarization) - E plane after processing - simulation, Renault and CNES measurement

\section{CONCLUSION}

This paper presents the use of post-processing techniques to improve antenna measurement results at low frequency in two different measurement systems. Due to the large wavelengths considered measurement results are strongly impacted by reflections coming from chamber walls and system components. Time filtering is better suited compared to modal or spatial filtering at these low frequencies. To reduce truncation effect in the Renault system, equivalent current approach is added. Obtained results are conclusive and underline the capability of indoor measurement systems to measure antenna at frequencies below their specifications.

\section{REFERENCES}

[1] Le Fur, G.; Duchesne, L.; Durand, L.; Bellion, A.; Belot, D. "Feasibility of indoor spherical near field antenna measurement facility in VHF range", Antenna Technology and Applied Electromagnetics (ANTEM), 2012 15th International Symposium on , vol., no., pp.1,7, 2528 June 2012.

[2] Le Fur, G.; Duchesne, L.; Durand, L.; Bellion, A.; Belot, D., Lopez J. M. "Design of a Spherical Near Field Antenna Measurement Facility in VHF Range" Antenna Measurement Techniques Association; AMTA, Columbus, 2013

[3] Metawell GmbH, metal sandwich technology http://www.metawell.de/

[4] GDR Ondes "Rapport sur le recensement des chambres anéchoïques française et leurs perspectives » 2010

[5] J. Appel-Hansen, "Reflectivity level of radio anechoic chambers," IEEE Trans. Antennas Propagt., vol. AP21, No. 4, pp. 490-498, Jul, 1973.

[6] A. Lehto, J. Tuovinen, and A. Räisänen, "Reflectivity level of anechoic chambers at $183 \mathrm{GHz}$," in Antennas Propagt. Soc. Int. Symp. 1990 Dallas, TX, May 7-11, pp. 1310-1313.

[7] E. N. Clouston, P. A. Langsford, and S. Evans, "Measurement of anechoic chamber reflections by time-domain techniques," IEE Proc. H, Microwaves Antennas Propagt., vol. 135, Pt. H, No. 2, pp. 93-97 Apr, 1988

[8] M. Nagatoshi, M. Hirose, H. Tanaka, S. Kurokawa, and H. Morishita, "A method of pattern measurement to cancel reflection waves in anechoic chamber," in Antennas Propagt. Soc. Int. Symp. 2008, San Diego, CA, Jul 5-11, pp. 1-4.

[9] D. A. Leatherwood, E. B. Joy, "Plane wave, pattern subtraction, range compensation," IEEE Trans. Antennas Propagat., vol. 49, No. 12, pp. 1843-1851, Dec, 2001.

[10] M. L. Van Blaricum and R. Mittra, "A technique for extracting the poles and residues of a system directly from its transient response," IEEE Trans. Antennas Propagat., vol. AP-23, No. 6, pp. 777-781, Nov., 1975.

[11] T. K. Sarkar, J. Nebat, D. D. Weiner, and V. K. Jain, "Suboptimal approximation/identification of transient waveforms from electromagnetic systems by pencil-of-function method," IEEE Trans. Antennas Propagat., vol. AP-28, No. 6, pp. 928-933, Nov., 1980.

[12] R. S. Adve, T. K. Sarkar, O. M. C. Pereira-Filho, and S. M. Rao, "Extrapolation of time.domain responses from three-dimensional conducting objects utilizing the matrix pencil technique," IEEE Trans. Antennas Propagat., vol. 45, No. 1, pp. 147-156, Jan., 1997.

[13] G. Hindman and A. Newell, "Reflection suppression in large spherica near-field range," in Antenna Meaurement. Techniques Assoc,. AMTA 2005, Newport, RI, October 30-November 4, pp. 270-275.

[14] F. J. Cano-Facila, S. Burgos, F. Martin, and M. Sierra-Castaner, "New reflection suppression method in antenna measurement systems based on diagnostic techniques," IEEE Trans. Antennas Propag., vol. 59, no. 3, pp. 941-949, Mar. 2011

[15] Foged, L.J.; Scialacqua, L.; Saccardi, F.; Mioc, F.; Iversen, P.O.; Shmidov, L.; Braun, R.; Araque Quijano, J.L.; Vecchi, G. "Comparison of echo suppression techniques in near field antenna measurement applications", Antennas and Propagation (EuCAP), 2013 7th European Conference on, On page(s): 3898 - 3902, Volume: Issue: , 8-12 April 2013.

[16] P. R. Rousseau, "The planar near-field measurement of a broad beam antenna using a synthetic subarray approach," in IEEE AP-S Symp. Digest., 1997, pp. 160-163.

[17] E. B. Joy, "Windows '96 for planar near-field measurements," in AMTA Proc. 1996, pp. 80-85.

[18] E. B. Joy, C. A. Rose, A. H. Tonning, and EE6254 Students, "Test-zone field quality in planar near-field measurements," in AMTA Proc. 1997, Williamsburg, VIR, Nov. 13-17, pp. 206-210.

[19] S. F. Gregson, C. G. Parini, and J. McCormick, "Development of wideangle pattern measurements using a probe-corrected polyplanar nearfield measurement technique," IEE Proc. Microw. Antennas Propag., vol. 152, pp. 563-572, no. 6, Dec. 2005.

[20] O. M. Bucci, G. D'Elia, and M. D. Migliore, "A new strategy to reduce the truncation error in near-field far-field transformation," Radio Sci. vol. 35 , no. 1, pp. 3-17, Jan.-Feb. 2000

[21] O. M. Bucci, C. Gennarelli, and C. Savarese, "Representation of electromagnetic fields over arbitrary surfaces by a finite and nonredundant number of samples," IEEE Trans. Antennas Propagat., vol. 46, no. 3, pp. 351-359, Mar. 1998.

[22] O. M. Bucci and M. D. Migliore, "A new method for avoiding the truncation error in near-field antennas measurements," IEEE Trans. Antennas Propag., vol. 54, no. 10, pp. 2940-2952, Oct. 2006.

[23] E. Martini, O. Breinbjerg, and S. Maci, "Reduction of truncation errors in planar near-field aperture antenna measurements using the Gerchberg-Papoulis algorithm," IEEE Trans. Antennas Propagat., vol. 56, no. 11, pp. 3485-3493, Nov., 2008.

[24] F. J. Cano-Facila, S. Pivnenko, and M. Sierra-Castaner, "Reduction of truncation error in planar, cylindrical and partial spherical near-field antenna measurements," International Journal of Antennas and Propagation, vol. 2012, Article ID 438727, 19 pages, 2012. doi:10.1155/2012/438727.

[25] Petre, P. and Sarkar, T.K., "Planar near-field to far-field transformation using an equivalent magnetic current approach", Antennas and Propagation, IEEE Transactions on, 1992, vol. 11.

[26] Satimo Insight software http://www.satimo.com/content/products/insight

[27] L.J. Foged, L. Scialacqua, F. Saccardi, F. Mioc,J. L. Araque Quijano, E. Martini, S. Maci, M. Sabbadini,G. Vecchi, "Comparative Investigation of Methods to Reduce Truncation Errors in Partial Spherical Near-Field Antenna Measurements", EuCAP 2012, Prague, Czech Republic.

[28] J. D. Young, D. E. Svoboda, and W. D. Burnside, "A comparison of time- and frequency-domain measurement techniques in antenna theory," IEEE Trans. Antennas Propagat., vol. 21, No. 4, pp. 581-583, Jul., 1973.

[29] G. A. Burrell and A. R. Jamieson, "Antenna radiation pattern measurement using time-to-frequency transformation (TFT) techniques," IEEE Trans. Antennas Propagat., vol. 21, No. 5, pp. 702-704, Sep., 1973.

[30] S. Loredo, M. R. Pino, F. Las-Heras, and T. K. Sarkar, "Echo identification and cancellation techniques for antenna measurement in non-anechoic test sites," IEEE Antennas Propagat. Mag., vol. 46, No. 1, pp. 100-107, Feb., 2004. 